\title{
Parathyroid hormone secretion in chronic human endogenous hypercortisolism
}

C.M.M. Lanna, F.J.A. Paula, R.M. Montenegro Jr., A.C. Moreira and M.C. Foss
Departamento de Clínica M édica, Faculdade de Medicina de Ribeirão Preto, Universidade de São Paulo, Ribeirão Preto, SP, Brasil

\section{Correspondence}

\section{M.C. Foss}

Departamento de Clínica Médica

FMRP, USP

Avenida Bandeirantes, 3900

14048-900 Ribeirão Preto, SP

Brasil

Fax: + 55-16-633-6695

E-mail: mcfoss@ fmrp.usp.br

Research supported by the Hospital das Clínicas, Faculdade de Medicina de Ribeirão Preto, USP, FAEPA, CNPq and CAPES. Publication supported by FAPESP.

Received August 24, 2001 Accepted December 10, 2001

\section{Abstract}

Osteoporosis is a common manifestation of Cushing's syndrome, but the mechanisms responsible for this abnormality have not been defined. With the objective of analyzing parathyroid hormone (PTH) secretion in chronic hypercortisolism $(\mathrm{CH})$, we evaluated 11 healthy subjects and 8 patients with $\mathrm{CH}, 6$ with Cushing's disease and 2 with adrenal adenoma. These volunteers were submitted to tests of PTH stimulation through hypocalcemia (EDTA), PTH suppression through hypercalcemia ( $i v$ and oral calcium), and evaluation of bone mineral density (BMD) by DEXA. During the test of PTH stimulation, the calcium and magnesium concentrations of the normal and $\mathrm{CH}$ groups were similar. Patients with $\mathrm{CH}$ showed an increased PTH response to the hypocalcemic stimulus compared to controls. PTH values were significantly higher in the $\mathrm{CH}$ group at $70(17.5 \pm 3.5$ vs $10.2 \pm 1.3$ $\mathrm{pmol} / \mathrm{l}, \mathrm{P}=0.04)$, and $120 \mathrm{~min}(26.1 \pm 5.9$ vs $11.3 \pm 1.9 \mathrm{pmol} / \mathrm{l}, \mathrm{P}=$ 0.008) of EDTA infusion. The area under the curve for PTH during EDTA infusion was also significantly higher in patients with $\mathrm{CH}$ than in normal subjects $\left(1867 \pm 453\right.$ and $\left.805 \pm 148 \mathrm{pmol}^{1^{-1}} 2 \mathrm{~h}^{-1}, \mathrm{P}=0.02\right)$. During the test of PTH suppression, calcium, magnesium and PTH levels of the patients with hypercortisolism and controls were similar. BMD was decreased in patients with hypercortisolism in the spine $\left(0.977 \pm 0.052\right.$ vs $1.205 \pm 0.038 \mathrm{~g} / \mathrm{cm}^{2}$ in controls, $\left.\mathrm{P}<0.01\right)$. In conclusion, our results show that subjects with $\mathrm{CH}$ present decreased bone mass mainly in trabecular bone. The use of dynamic tests permitted the detection of increased PTH secretion in response to a hypocalcemic stimulus in $\mathrm{CH}$ patients that may probably be involved in the occurrence of osteoporosis in this state.

\section{Introduction}

Chronic hypercortisolism $(\mathrm{CH})$ has been considered to be the most frequent cause of secondary osteoporosis. Compressive vertebral fractures occur in 30 to $35 \%$ of patients with Cushing's syndrome and the risk of femoral neck fractures is increased by $50 \%$

\section{Key words}

- Parathyroid hormone

- Calcium

- EDTA

- Hypercortisolism

- Cushing's syndrome

- Osteoporosis in this group (1).

Great interest in the study of the causal mechanisms of glucocorticoid-induced bone loss has arisen over the last few years. Some investigators have suggested direct mechanisms involving a reduction of osteoblastic activity and/or increased osteoclastic action $(2,3)$. Others have indicated that the loss of 
bone mass may be secondary to indirect factors such as a decrease of gonadal steroid levels and calciotropic hormones or to alterations in growth factors such as insulin-like growth factor I and cytokines (4-9).

The effect of parathyroid hormone (PTH) on the etiopathogenesis of glucocorticoidinduced osteoporosis is controversial. In different studies, normal and elevated PTH levels have been demonstrated in hypercortisolism under basal conditions (4,5,10-12). Normal levels are attributed to a direct osteolytic action of glucocorticoids, increasing the calcium flow from bones to the circulation, whereas the increased PTH levels are justified by the direct trophic action of glucocorticoids on the parathyroids, or indirectly by a reduction of intestinal absorption and/or an increase of renal calcium excretion.

The objective of the present study was to evaluate PTH secretion through dynamic tests and bone mineral density (BMD) in patients with chronic endogenous hypercortisolism.

\section{Subjects and Methods}

Eleven healthy subjects, 8 women and 3 men (control group), and 8 patients with $\mathrm{CH}$, 7 women and 1 man, 6 with pituitary disease and 2 with adrenal adenoma ( $\mathrm{CH}$ group), were studied. The groups did not differ significantly in terms of age, weight, height or body mass index. Their clinical characteristics are shown in Table 1. None of the subjects studied had a personal or family history of liver, renal or osteometabolic diseases or had used any other medication capable of interfering with bone metabolism.

The study was approved by the Ethics Committee of the University Hospital, School of Medicine of Ribeirão Preto, University of São Paulo, and all subjects gave written informed consent to participate.

The volunteers were submitted to a test of PTH stimulation through the induction of hypocalcemia by intravenous (iv) infusion of disodium ethylenediaminetetraacetic acid (EDTA), to tests of PTH suppression through the induction of hypercalcemia by $i v$ and oral calcium administration (13), and to evaluation of BMD by double-energy X-ray absorptiometry (DEXA, Sophos, LXRA, Paris, France).

The studies were performed in the morning after a 12-h fast on different days. A superficial vein was punctured in each arm (one for blood sample collection and the other for infusion) and after $30 \mathrm{~min}$ of rest,

Table 1. Clinical characteristics of patients with chronic hypercortisolism $(\mathrm{CH})$ and healthy subjects (controls).

\begin{tabular}{lcccccc}
\hline & Sex & Age (years) & Weight $(\mathrm{kg})$ & Height $(\mathrm{cm})$ & BMI $\left(\mathrm{kg} / \mathrm{m}^{2}\right)$ & Etiology of CH \\
\hline CH patients & & & & & & \\
1 & $\mathrm{~F}$ & 32 & 98.7 & 159.0 & 39.0 & Adrenal adenoma \\
2 & $\mathrm{~F}$ & 29 & 52.2 & 150.5 & 23.2 & Adrenal adenoma \\
3 & $\mathrm{~F}$ & 30 & 68.1 & 145.0 & 32.4 & Cushing's syndrome \\
4 & $\mathrm{~F}$ & 23 & 53.0 & 150.0 & 23.5 & Cushing's syndrome \\
5 & $\mathrm{~F}$ & 21 & 73.8 & 159.0 & 29.2 & Cushing's syndrome \\
6 & $\mathrm{~F}$ & 24 & 67.2 & 160.0 & 23.4 & Cushing's syndrome \\
7 & $\mathrm{~F}$ & 34 & 99.7 & 171.5 & 33.9 & Cushing's syndrome \\
8 & $\mathrm{M}$ & 27 & 72.5 & 175.0 & 23.7 & Cushing's syndrome \\
Mean \pm SEM & $27.5 \pm 1.6$ & $73.1 \pm 3.3$ & $158.7 \pm 2.7$ & $28.5 \pm 2.1$ & \\
Controls & & & & & \\
\multicolumn{2}{l}{ Mean \pm SEM } & $31.7 \pm 2.5$ & $69.2 \pm 5.5$ & $164.3 \pm 3.4$ & $25.9 \pm 2.6$ & \\
\hline
\end{tabular}

$\mathrm{BMI}=$ body mass index. Controls: $\mathrm{N}=11(8 \mathrm{~F}, 3 \mathrm{M})$. 
blood samples were drawn to determine plasma cortisol, LH, FSH, testosterone, androstenedione, DHEA-S, estradiol, prolactin, and free $\mathrm{T}_{4}$ and TSH levels.

In the PTH stimulation test, venous blood samples were collected every $10 \mathrm{~min}$ for the determination of ionized calcium, magnesium and intact PTH during a basal period (30 min) and after infusion of EDTA solution. The EDTA solution was prepared immediately before administration and contained $30 \mathrm{mg} / \mathrm{kg}$ weight EDTA, $2.7 \mathrm{mg} / \mathrm{kg}$ weight lidocaine, and a $5 \%$ glucose solution in a total volume of $200 \mathrm{ml}$. This solution was totally infused over a period of $2 \mathrm{~h}$ (Harvard Apparatus) into the contralateral arm to that used for blood collection using a continuous infusion pump.

In the $i v$ test of PTH suppression, venous blood samples were collected every $10 \mathrm{~min}$ during the first hour and every $20 \mathrm{~min}$ thereafter for the determination of ionized calcium, magnesium and intact PTH. After 30 min (basal period), a solution containing 5.0 $\mathrm{mg} / \mathrm{kg}$ calcium gluconate and $5 \%$ glucose in a total volume of $100 \mathrm{ml}$ was administered over a period of $2 \mathrm{~h}$, as previously described for the test of PTH stimulation.

In the oral test of PTH suppression, venous blood samples were collected every $30 \mathrm{~min}$ for the determination of ionized calcium, magnesium and intact PTH during a basal period ( 2 collections) and after the oral administration of $1 \mathrm{~g}$ of elemental calcium (2 tablets of Calcium Sandoz FTM, Basel, Switzerland) over a period of $3 \mathrm{~h}$.

Ionized calcium (normal range: 1.14-1.29 $\mathrm{mmol} / \mathrm{l}$ ) was measured in blood obtained with a 3-ml syringe containing calciumtitrated heparin $\left(2560^{\mathrm{TM}}\right.$ Radiometer, Copenhagen, Denmark) using an analyzer with a calcium-specific electrode (Radiometer ICA II, Copenhagen, Denmark). Samples were collected anaerobically and measurements were made immediately after collection. Intact PTH was determined in serum by immunochemiluminescence (ICMA, Immu- lite, Diagnostic Products Corporation, Los Angeles, CA, USA). The intra- and interassay coefficients of variation and the minimum detectable dose were $3.3 \%, 10.2 \%$ and $1 \mathrm{pg} / \mathrm{ml}$, respectively. Serum samples for the determination of intact PTH were separated in a refrigerated centrifuge and frozen at $-70^{\circ} \mathrm{C}$ until the day for determination. Serum magnesium (normal range: $0.8-1.3 \mathrm{mmol} / \mathrm{l}$ ) was determined in duplicate by atomic absorption spectrophotometry using a PerkinElmer apparatus (Perkin Elmer, Norwalk, CT, USA). LH, FSH, testosterone, androstenedione, DHEA-S, cortisol, estradiol, and prolactin were determined by radioimmu-
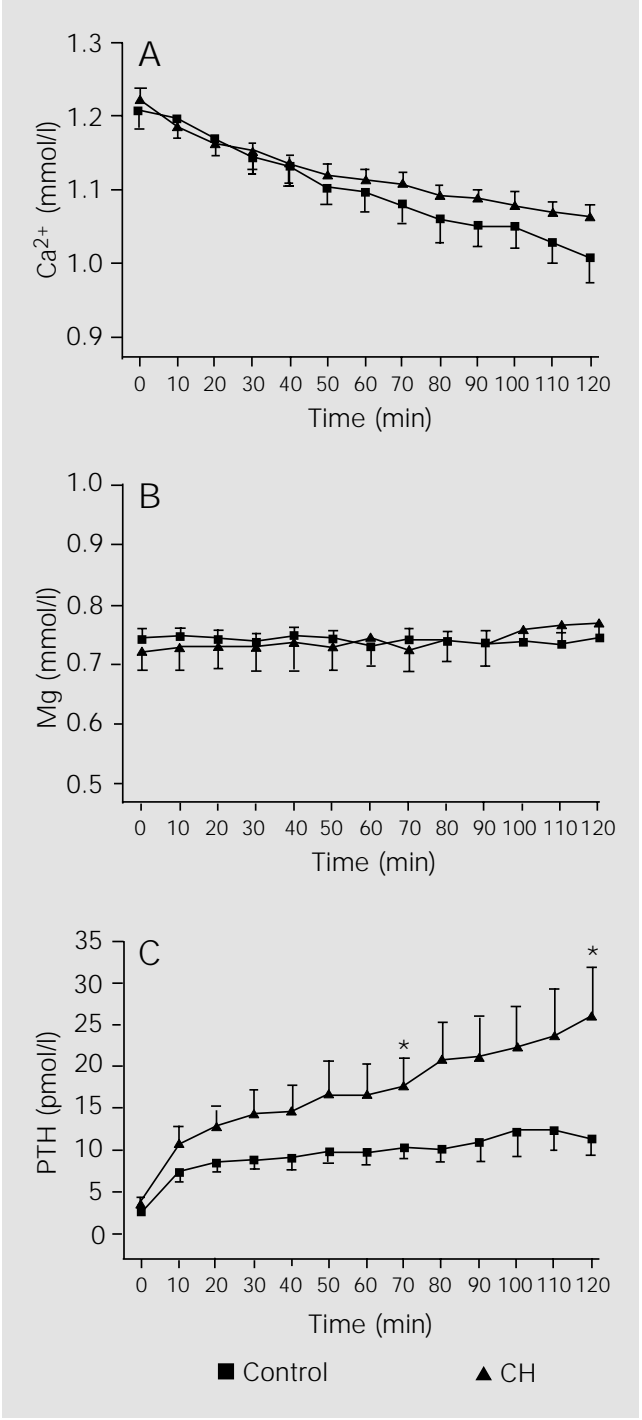

Figure 1. Test of parathyroid hormone (PTH) stimulation in hypercortisolism. Blood calcium (A), magnesium (B), and PTH concentrations (C) of patients with chronic hypercortisolism (CH) and normal subjects (controls), before (time $-30,-20,-10$, 0 ) and for $2 \mathrm{~h}$ after EDTA infusion (30 mg/kg weight). Data are reported as means \pm SEM. $* \mathrm{P}<0.05$ compared to controls (Mann-Whitney test). 
Figure 2. Intravenous test of parathyroid hormone (PTH) suppression in hypercortisolism. Blood calcium (A), magnesium (B), and PTH concentrations (C) of patients with chronic hypercortisolism $(\mathrm{CH})$ and normal subjects (controls), before (time - 30 , $-20,-10,0)$ and for $2 \mathrm{~h}$ after calcium gluconate infusion $(5 \mathrm{mg} /$ kg weight). Data are reported as means \pm SEM. There were no significant differences between groups. noassay. Free $\mathrm{T}_{4}$ and TSH were determined by ICMA.

BMD was measured in the spine (L2 and L4), femoral neck and Ward triangle by DEXA.

The results are reported as means \pm SEM. Data were analyzed statistically by the twotailed Mann-Whitney test for comparison between different groups, and by the Friedman and Dunn tests for analysis of variance with multiple comparisons of the functional tests. The area under the curve (AUC) was calculated for each curve response by the trapezoidal method. The level of statistical significance was set at $5 \%(\mathrm{P}<0.05)$.
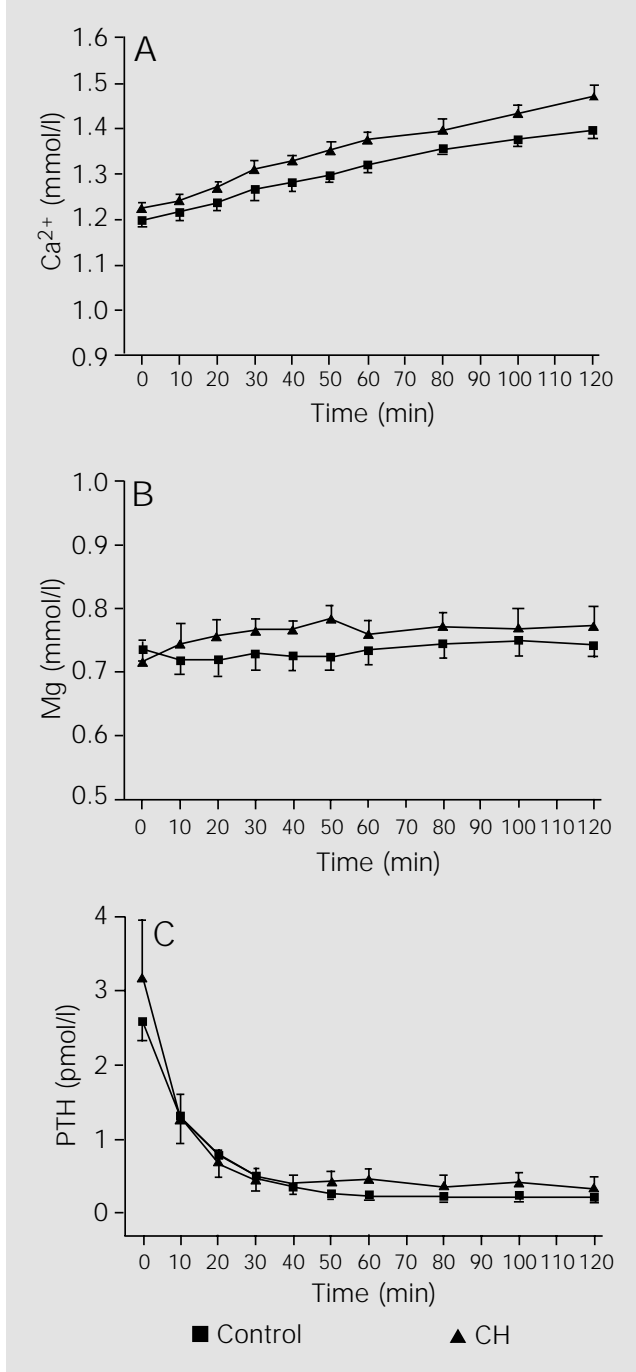

\section{Results}

Eight controls and 8 patients with $\mathrm{CH}$ were submitted to the test of PTH stimulation by EDTA infusion. During this test, the mean basal levels of ionized calcium were $1.20 \pm 0.02$ in the control group and $1.22 \pm$ $0.01 \mathrm{mmol} / \mathrm{l}$ in the $\mathrm{CH}$ group, with a similar decrease in both groups after EDTA infusion (Figure 1A). The mean basal levels of magnesium were $0.74 \pm 0.02$ in controls and 0.72 $\pm 0.03 \mathrm{mmol} / \mathrm{l}$ in $\mathrm{CH}$ patients, with no significant difference between groups during the test (Figure 1B). In the same test mean basal PTH levels were similar between groups $(2.62 \pm 0.5$ in normal subjects and $3.4 \pm 0.8$ $\mathrm{pmol} / \mathrm{l}$ in $\mathrm{CH}$ patients). After the stimulus, PTH values were significantly higher at 70 (17.5 \pm 3.5 vs $10.2 \pm 1.3 \mathrm{pmol} / \mathrm{l}, \mathrm{P}=0.04)$, and $120 \mathrm{~min}(26.1 \pm 5.9 \mathrm{vs} 11.3 \pm 1.9 \mathrm{pmol} / \mathrm{l}$, $\mathrm{P}=0.008)$ of EDTA infusion in the $\mathrm{CH}$ group compared to controls. The AUC of PTH during EDTA infusion was also significantly higher in patients with $\mathrm{CH}$ than in normal subjects $(1867 \pm 453$ and $805 \pm 148$ pmol $\mathrm{l}^{-1} 2 \mathrm{~h}^{-1}, \mathrm{P}=0.02$ ) (Figure 1C).

Seven normal subjects and 6 patients with $\mathrm{CH}$ were submitted to the $i v$ test of PTH suppression by calcium gluconate infusion. In this test, the mean basal levels of ionized calcium were $1.20 \pm 0.01$ in controls and $1.22 \pm 0.01 \mathrm{mmol} / \mathrm{l}$ in $\mathrm{CH}$ patients. After calcium infusion, $\mathrm{CH}$ patients reached higher levels of ionized calcium at 50,60, 100 and 120 min of the test, although when the AUC of ionized calcium levels after calcium infusion is considered there was no difference between groups $(13.6 \pm 1.2$ vs $16.2 \pm 1.2$ mmol l-1 $2 \mathrm{~h}^{-1}$ ) (Figure 2A). The mean basal values of magnesium during that test did not differ significantly between controls and $\mathrm{CH}$ patients $(0.74 \pm 0.02$ vs $0.72 \pm 0.03 \mathrm{mmol} / \mathrm{l})$. During calcium infusion, magnesium levels were relatively stable, with similar serum concentrations in both groups (Figure 2B). No statistically significant differences in basal PTH levels were observed between groups 
( $2.6 \pm 0.2$ in controls and $3.5 \pm 0.9 \mathrm{pmol} / \mathrm{l}$ in $\mathrm{CH}$ patients). After calcium infusion there was a similar decrease in PTH concentrations in both groups (Figure 2C).

Seven controls and $7 \mathrm{CH}$ patients were submitted to the oral test of PTH suppression. In this test, ionized calcium levels were similar between groups both under basal conditions $(1.21 \pm 0.01$ in controls and 1.19 $\pm 0.03 \mathrm{mmol} / \mathrm{l}$ in $\mathrm{CH}$ patients) and after calcium overload (Figure 3A). There was no difference in magnesium levels between groups $(0.74 \pm 0.02$ and $0.75 \pm 0.02 \mathrm{mmol} / \mathrm{l}$ in normal subjects and patients with $\mathrm{CH}$, respectively) with similar concentrations of this ion after calcium ingestion (Figure 3B). Normal and $\mathrm{CH}$ subjects presented equivalent basal PTH concentrations ( $2.9 \pm 0.5$ and $3.1 \pm 0.6 \mathrm{pmol} / \mathrm{l}$, respectively). After calcium overload, there was a significant reduction in PTH levels in both groups, with no significant differences between them (Figure 3C).

Patients with $\mathrm{CH}$ showed significantly decreased BMD in the spine when compared to the control group $(0.977 \pm 0.052$ vs 1.205 $\left.\pm 0.038 \mathrm{~g} / \mathrm{cm}^{2}, \mathrm{P}<0.01\right)$, but no difference from controls in the femoral neck $(0.845 \pm$ 0.044 vs $\left.0.937 \pm 0.046 \mathrm{~g} / \mathrm{cm}^{2}\right)$ or in Ward triangle $(0.746 \pm 0.047$ vs $0.856 \pm 0.029 \mathrm{~g} /$ $\mathrm{cm}^{2}$ ).

Considering that sex can interfere with bone mass, the BMD and androgen levels of women were analyzed separately. Seven of 11 controls and 7 of 8 patients with hypercortisolism were females. Women with $\mathrm{CH}$ presented significantly decreased BMD in the spine when compared to the control group $\left(0.950 \pm 0.051\right.$ vs $1.199 \pm 0.048 \mathrm{~g} / \mathrm{cm}^{2}$, $\mathrm{P}<0.01$ ), but no difference from normal women in the femoral neck $(0.823 \pm 0.044 v s$ $0.900 \pm 0.048 \mathrm{~g} / \mathrm{cm}^{2}$ ) or in Ward triangle $\left(0.731 \pm 0.052\right.$ vs $\left.0.836 \pm 0.034 \mathrm{~g} / \mathrm{cm}^{2}\right)$.

Androstenedione levels were significantly higher in $\mathrm{CH}$ group women $(6.3 \pm 1.7$ vs 2.4 $\pm 0.5 \mathrm{nmol} / \mathrm{l}, \mathrm{P}=0.03$ ), who also showed a tendency to more elevated testosterone lev- els $(2.7 \pm 0.6$ vs $1.7 \pm 0.3 \mathrm{nmol} / \mathrm{l}, \mathrm{P}=0.09)$ compared to control women. Female patients with $\mathrm{CH}$ and normal women presented similar DHEA-S $(5.4 \pm 1.4$ vs $2.7 \pm 0.1$ $\mu \mathrm{mol} / \mathrm{l})$ and estradiol levels $(295.5 \pm 38.5 \mathrm{vs}$ $294.8 \pm 57.6 \mathrm{pmol} / \mathrm{l})$.

\section{Discussion}

The mechanisms involved in glucocorticoid-induced osteoporosis have been extensively investigated in the last years. In vitro studies have reported that these steroids can act on bone by remodeling cells, reducing bone formation (2) and stimulating bone

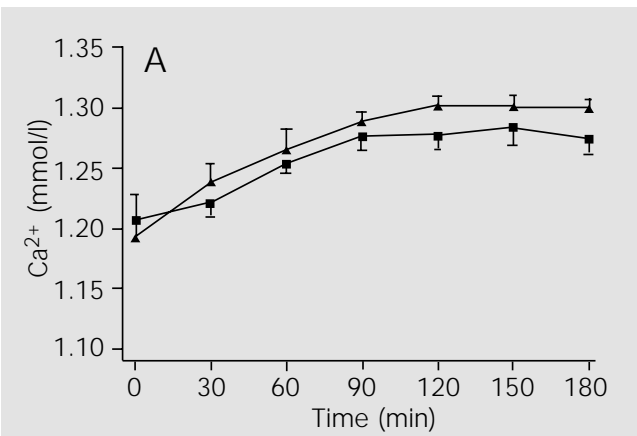

Figure 3. Oral test of parathyroid hormone (PTH) suppression in hypercortisolism. Blood calcium $(\mathrm{A})$, magnesium $(\mathrm{B})$, and $\mathrm{PTH}$ concentrations (C) of patients with chronic hypercortisolism $(\mathrm{CH})$ and normal subjects (controls), before (time -30, 0) and for $3 \mathrm{~h}$ after ingestion of $1 \mathrm{~g}$ of elemental calcium. Data are reported as means \pm SEM. There were no significant differences between groups.
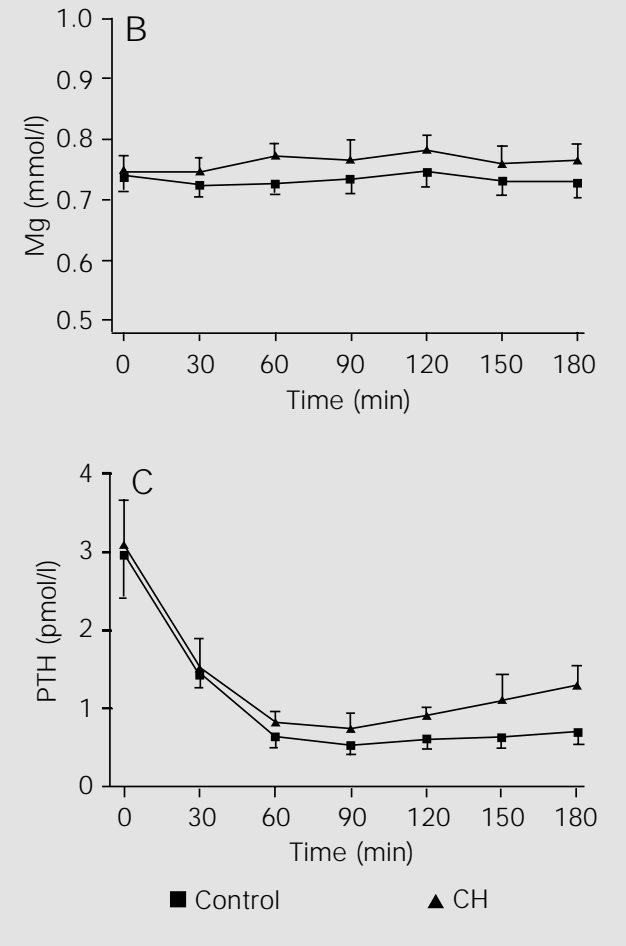
resorption (3). In addition to exerting these direct actions on bone, these steroids can potentially affect the process of bone remodeling in an indirect manner by interfering with the secretion of calciotropic hormones and sex steroids.

Osteoporosis detected in patients with hypercortisolism is usually attributed to a decreased production of gonadal steroids. It is well known that androgens have an important anabolic effect on bone mass. The hypogonadism of Cushing's syndrome is the result of a direct suppressive action of glucocorticoids on gonadal steroidogenesis, $\mathrm{GnRH}$ release or pituitary sensitivity to GnRH (6). However, Cushing's syndrome is a heterogeneous disturbance. In contrast to exogenous hypercortisolism (iatrogenic causes), pituitary disease usually presents variable degrees of adrenal hyperandrogenism (14). Thus, high ACTH levels stimulate adrenal production of androgen, and this action usually exceeds the inhibitory effect of glucocorticoids on ovarian production of androgens, resulting in hyperandrogenism. In the present study, $\mathrm{CH}$ patients presented different androgen profiles. Thus, evaluation of women with $\mathrm{CH}$ showed significantly higher androstenedione levels and a tendency to more elevated testosterone levels, and even so, the spinal BMD of women with $\mathrm{CH}$ was lower than that of normal women. Therefore, androgen deficiency by itself does not explain the occurrence of osteoporosis in these patients. Previous studies have suggested that DHEA-S is an important hormone for the maintenance of bone mass. During aging, the fall in DHEA-S levels has been implicated in the occurrence of osteoporosis (15). In our study, similar levels of DHEA-S were observed in patients with $\mathrm{CH}$ and controls. Therefore, our results indicate that the loss of bone mass in hypercortisolism occurs even in subjects that maintain increased levels of androgens of adrenal origin. On the other hand, reduced androgen levels may be an additional factor accelerat- ing bone loss in exogenous hypercortisolism, in which lack of androgen production usually occurs.

The importance of estradiol to the maintenance of bone mass has been emphasized in recent years. It was demonstrated in some studies that this hormone has a trophic effect on bones even in males $(16,17)$. In the present study, $\mathrm{CH}$ patients did not present lower estradiol levels when compared to controls. This was probably due to the peripheral (adipose tissue) conversion of androgens to female sex steroids. Once again, our results indicate that hypogonadism is not the main causal factor for the occurrence of osteoporosis in chronic endogenous hypercortisolism.

Our results show that the basal PTH levels of patients with endogenous hypercortisolism and healthy subjects were similar. During the induction of hypocalcemia, patients with $\mathrm{CH}$ presented a significantly higher PTH secretion than controls. These data suggest that measurement of basal PTH levels is insufficient for the evaluation of abnormalities in PTH secretion in CH. Different results were described by Chiodini et al. (18). These authors demonstrated elevated basal PTH levels, reduced bone mass and increased bone turnover markers in 18 eugonadal women with Cushing's syndrome compared to controls. Nevertheless, in the present study alterations in PTH secretion were evidenced by the PTH stimulation test, suggesting that this method is more adequate for the evaluation of the parathyroid secretory reserve in endogenous Cushing's syndrome.

Some investigators have reported that glucocorticoids have a direct stimulating effect on the parathyroids, and act through specific receptors present there. Parathyroid hyperplasia and increased PTH levels with the administration of cortisone acetate have been demonstrated in experimental studies on animals (19) and in patients with Cushing's syndrome (20). More recently, Karmali et al. (21) suggested that the action of gluco- 
corticoids on the parathyroids may be caused by a reduction of the number of 1,25-dihydroxyvitamin D receptors, thus reducing the inhibitory activity of 1,25-dihydroxyvitamin $\mathrm{D}$ on this gland. The PTH increase may also be due to a metabolic adaptation in response to a decrease in the intestinal absorption and/ or an elevation in the urinary excretion of calcium. Abnormalities in intestinal calcium absorption caused by glucocorticoids may be related to several mechanisms. These steroids may act directly on the gut, provoking a decrease in intestinal calcium absorption, and resulting in hypocalcemia which is capable of stimulating the secretion of PTH (22). Glucocorticoids can inhibit the action of vitamin $\mathrm{D}$, decreasing the number of its receptors or increasing its degradation (23). Calcium-binding proteins are fundamental in the intestinal mucosa to allow calcium absorption. According to Kimberg (24), vitamin $\mathrm{D}$ is involved in the induction of the formation of these proteins and the glucocorticoids have an opposite effect. Corradino and Fullmer (25) verified that the genetic expression of calbindin-D28K, a protein involved in calcium absorption in the intestinal mucosa, is reduced in subjects exposed to high glucocorticoid concentrations, thus justifying the effect of these steroids on intestinal calcium absorption. Besides the decrease in intestinal calcium absorption, glu- cocorticoids cause a reduction in tubular calcium reabsorption, interfering with the balance of this ion, and could result in hypocalcemia capable of stimulating PTH secretion.

Our results showed that subjects with $\mathrm{CH}$ present decreased bone mass mainly in trabecular bone. Although these patients presented elevated levels of androgens compared to controls, this increase did not seem to be sufficient to counterbalance the osteocatabolic action of glucocorticoids. In this study, the use of dynamic tests permitted the detection of increased PTH secretion in $\mathrm{CH}$ patients. However, the data obtained did not allow us to conclude if this phenomenon was due to a direct or indirect action on the parathyroid gland. Nevertheless, it is possible to assume that the altered PTH secretion found here is involved in the osteopenia developed by these patients.

\section{Acknowledgments}

The authors are grateful to Prof. Tadao Shuhama for the magnesium determinations, to Nadia Bittar Garcia, Lucimara Bueno, Adriana Rossi, Sebastião Lazaro Brandão Filho and José Roberto da Silva for technical assistance, and to Alex Adriano da Silva for secretarial assistance.

\section{References}

1. Fitzpatrick LA (1989). Osteoporosis: prevention and treatment. Progress in Clinical and Biological Research, 320: 263-282.

2. Canalis E \& Avioli L (1992). Effects of deflazacort on aspects of bone formation in cultures of intact calvarie and osteoblastenriched cells. J oumal of Bone and Mineral Research, 7: 1085-1092.

3. Reid RI (1989). Pathogenesis and treatment of steroid osteoporosis. Clinical Endocrinology, 30: 83-103.

4. Hahn JT, Halstead LR \& Baran DT (1981). Effects of short term glucocorticoid administration on intestinal calcium absorp- tion and circulating vitamin $\mathrm{D}$ metabolite concentrations in man. J ournal of Clinical Endocrinology and Metabolism, 52: 111115.

5. Hattersley AT, Meeran $K$, Burrin Hill $P$, Shiner R \& Ibbertson K (1994). The effect of long and short-term corticosteroids on plasma calcitonin and parathyroid hormone levels. Calcified Tissue International, 54: 198-202.

6. Veldhuis J D, Lizarralde G \& Iranmanesh A (1992). Divergent effects of short-term glucocorticoid excess on the gonadotropic and somatotropic axes in normal men.
J ournal of Clinical Endocrinology and Metabolism, 74: 96-102.

7. Marusic A \& Raisz L (1991). Cortisol modulates the actions of interleukin-1 alpha on bone formation, resorption and prostaglandin production in cultured mouse parietal bones. Endocrinology, 129: 2699-2706.

8. Ernst M \& Froesch ER (1988). Growth hormone dependent stimulation of osteoblast-like cells in senum-free cultures via local synthesis of insulin-like growth factor. Biochemical and Biophysical Research Communications, 151: 142-147. 
9. McCarthy TL, Centrella M \& Canalis E (1990). Cortisol limits the synthesis of insulin-like growth factor-I in skeletal cells. Endocrinology, 126: 1569-1575.

10. Fucik RF, Kukreja SC, Hargis GK, Bowser NE, Henderson WJ \& Williams GA (1975). Effect of glucocorticoids on function of the parathyroid glands in man. J ournal of Clinical Endocrinology and Metabolism, 40: 152-155.

11. Bikle DD \& Pillai S (1993). Vitamin D, calcium and epidermal differentiation. Endocrine Reviews, 14: 3-19.

12. Seeman E, Kumar R, Hunder GG, Scott $M$, Heath III H \& Riggs BL (1980). Production, degradation, and circulation levels of 1,25-dihydroxyvitamin $D$ in health and chronic glucocorticoid excess. J oumal of Clinical Investigation, 66: 664-669.

13. Lips P, Netelenbos J C, van Doorn L, Hackeng WH \& Lips CJ (1991). Stimulation and suppression of intact parathyroid hormone (PTH1-84) in normal subjects and hyperparathyroid patients. Clinical Endocrinology, 35: 35-40.

14. Moreira AC (1987). Plasmatic dehydroepiandrosterone sulfate in the etiologic diagnosis of Cushing's syndrome: correlation with plasma ACTH. Arquivos Brasileiros de Endocrinologia e Metabologia, 31: 53-
56.

15. Davis SR \& Burger HG (1996). Androgens and the postmenopausal woman. J ournal of Clinical Endocrinology and Metabolism, 81: 2759-2763.

16. Riggs BL (2000). The mechanisms of estrogen regulation of bone resorption. J ournal of Clinical Investigation, 106: 1203-1204.

17. Faustini-Fustini $M$, Rochira $V \&$ Carani $C$ (1999). Oestrogen deficiency in men: Where are we today? European J ournal of Endocrinology, 140: 111-129.

18. Chiodini I, Camevale V, Torlontano M, Fusilli S, Guglielmi G, Pileri M, Modoni S, Di Giorgio A, Liuzzi A, Minisola S, Cammisa M, Trischitta V \& Scillitani A (1998). Alterations of bone tumover and bone mass at different skeletal sites due to pure glucocorticoid excess: study in eumenorrheic patients with Cushing's syndrome. J ournal of Clinical Endocrinology and Metabolism, 83: 1863-1867.

19. Williams GA, Peterson WC, Bowser N, Henderson WJ , Hargis GK \& Martinez NJ (1974). Interrelationship of parathyroid and adrenocortical function in calcium homeostasis in the rat. Endocrinology, 95: 707-712.

20. Wajchenberg BL, Quintão ER \& Liberman
B (1965). Antagonism between adrenal steroids and parathyroid hormone. J ournal of Clinical Endocrinology and Metabolism, 25: 1677-1681.

21. Karmali R, Farrow $S \&$ Hewison M (1989). Effects of 1,25 dihydroxyvitamin $D_{3}$ and cortisol on bovine and human parathyroid cells. J oumal of Endocrinology, 123: 137142.

22. Gennari $C$, Imbimbo B, Montagnani $M$, Bemini M, Nardi P \& Avioli V (1984). Effects of prednisone and deflazacort on mineral metabolism and parathyroid hormone activity in humans. J oumal of Clinical Investigation, 36: 245-252.

23. Chen $\mathrm{TL}$, Cone $\mathrm{CM} \&$ \& Morey-Holton $\mathrm{E}$ (1982). $1 \alpha, 25$-Dihydroxyvitamin $\mathrm{D}_{3}$ receptors in cultured rat osteoblast-like cells. Glucocorticoid treatment increases receptor content. J ournal of Biological Chemistry, 258: 4350-4355.

24. Kimberg DV (1969). Effects of vitamin D and steroid hormones on the active transport of calcium by the intestine. New England J oumal of Medicine, 280: 1396-1405.

25. Corradino RA \& Fullmer CB (1991). Positive cotranscriptional regulation of intestinal calbindin-D28K gene expression by 1,25-dihydroxy-vitamin $\mathrm{D}_{3}$ and glucocorticoids. Endocrinology, 128: 944-950. 